\title{
The Role of the Upper Airway in Contributing to Respiratory Responses during Experimental Seizures in Piglets ${ }^{1}$
}

\author{
THOMAS E. TERNDRUP, MATTHEW E. GREGORY, AND WAYNE E. FORDYCE \\ Department of Emergency Medicine, State University of New York Health Science Center at Syracuse,
} Syracuse, New York 13210 \begin{abstract}
Recent data demonstrating stimulation of respiration during
seizures are at odds with the frequent clinical finding of respiratory impairment in patients with generalized seizures. To determine the role of the upper airway in contributing to these clinical observations, a study was performed in 12 weanling piglets. An arterial catheter and epidural electrodes were placed in ketamineanesthetized piglets. In intact piglets, all airflow was measured through a snug-fitting nasal mask whereas pressure was measured with a subglottic catheter. Tracheostomized piglets had airflow and pressure measured at the trachea. Seizures were induced with i.v. injections of pentylenetetrazol. Peak inspiratory flow resistance was calculated by averaging three epochs of five to seven consecutive breaths. Epochs of greater than $20 \mathrm{~s}$ in duration with a tidal volume of $<10 \mathrm{~mL}$ were termed apnea. Apnea was considered central when airway pressure was $>-2$ $\mathrm{cm} \mathrm{H}_{2} \mathrm{O}$ and obstructive when $<-10 \mathrm{~cm} \mathrm{H}_{2} \mathrm{O}$. After 20 min of
\end{abstract}

untreated seizures, intact piglets had significant respiratory and metabolic acidosis, whereas tracheostomized piglets had significant increases in Ve and mild metabolic acidosis. Apnea and obstruction were observed frequently in intact piglets. Resistance was unchanged during seizures in tracheostomized piglets, whereas a nearly 4-fold increase in inspiratory resistance was observed in intact piglets. We conclude that upper airway patency and resistances are important determinants of respiratory responses during generalized seizures in piglets. (Pediatr Res 38: 61-66, 1995)

ECoG, electrocorticogram

Abbreviations

Ve, minute ventilation

ANOVA, analysis of variance

SIDS, sudden infant death syndrome
Respiratory complications during generalized tonic-clonic seizures in humans are both common and severe (1-3). Typically, epileptic patients develop cyanosis, apnea, and impaired ventilation in association with generalized tonic-clonic seizure activity (4). An important subset of epileptic patients develop aspiration or respiratory failure, particularly children, during prolonged generalized seizures and their treatment $(2,3)$. Sudden death in epilepsy is accompanied by pathologic changes including intrathoracic petechiae and pulmonary edema and indicate the possibility of terminal respiratory efforts against a collapsed upper airway $(5,6)$. The mechanism of respiratory impairment during seizures has not been satisfactorily investigated.

However, recent data from both adult cats and weanling piglets demonstrates increased central respiratory drive and

Received April 13, 1994; accepted February 6, 1995

Correspondence: Dr. Terndrup, Department of Emergency Medicine, SUNY Health Science Center, 750 East Adams Street, Syracuse, NY 13210.

Supported by grants from the Research Foundation of New York (BRSG no. 211E300-T) and the Emergency Medicine Foundation Career Development Award.

${ }^{1}$ Presented in part at the Society for Pediatric Research/American Pediatric Association Annual Meeting, May 4, 1993, Washington, DC minute ventilation during experimental seizures $(7-10)$. Progressive respiratory stimulation during seizures has been reported in subcortical penicillin $(7,9,11)$, i.v. bicuculline (8), and i.v. pentylenetetrazol (10) models. These initial studies have used tracheostomized models which have bypassed the upper airway. Because the upper airway of mammals requires patency for successful airflow (12), increases in upper airway resistances and obstruction might contribute to respiratory compromise during seizures.

The purpose of the present study was to compare respiratory responses in intact versus tracheostomized piglets during experimental, generalized seizures to determine the role of the upper airway in these respiratory responses.

\section{METHODS}

This study was approved by the Committee for the Humane Use of Animals. Fasted, mixed-breed, domestic piglets received ketamine, $22 \mathrm{mg} / \mathrm{kg}$, and acepromazine, $1.1 \mathrm{mg} / \mathrm{kg}$, intramuscularly, approximately $20 \mathrm{~min}$ after glycopyrrolate, $0.5 \mathrm{mg}$. They were placed supine on a V-shaped board, and their extremities were restrained. An infusion of ketamine 
hydrochloride, $0.2-0.25 \mathrm{mg} / \mathrm{kg} / \mathrm{min}$, was provided for maintenance anesthesia. During surgical preparation, additional small boluses of ketamine, $0.05-0.1 \mathrm{mg} / \mathrm{kg}$, were occasionally administered to ensure adequate anesthesia. The infusion rate was adjusted to provide light anesthesia and was not adjusted after the completion of instrumentation. The anesthesia level was such that piglets were responsive to nocioception and had an active gag reflex to the introduction of a laryngoscope blade. Lidocaine, $1 \%$, was infiltrated into the skin at the sites of any incisions to minimize pain perception.

Through a lateral neck incision, an external jugular vein and common carotid artery were cannulated using polyethylene catheters. The arterial catheter was connected to a pressure transducer and zeroed at mid chest level. Systolic arterial pressure was monitored throughout the study and was always greater than $100 \mathrm{~mm} \mathrm{Hg}$. The rectal temperature was monitored (44-TD, Yellow Springs, $\mathrm{OH}$ ) and servo-controlled between 37 and $39^{\circ} \mathrm{C}$ with a warming blanket and cooling mechanism. Two, epidural, silver ball electrodes were placed for recording of the ECoG, by raising a scalp flap and placing the electrodes through paired, temporal craniotomy sites.

A midline, vertical neck incision was performed allowing, in tracheostomized piglets, introduction of a shortened endotracheal tube (4.5-mm internal diameter), which was secured above the carina. For intact piglets, a tiny tracheostomy was placed at the third tracheal ring, a catheter was advanced through this site in a cephalad direction, and secured. The subglottic position of the tracheal catheter was verified by direct laryngoscopy and at postmortem examination. A pursestring suture was placed around the catheter at the tracheostomy site to prevent air leaks. The lips were sealed with cyanoacrylate or silicone and sutured closed taking care to avoid entrapping the tongue. A snug fitting, clear mask was secured over the protrusion formed by the nasal rim.

Airway pressure was monitored in all piglets with an in-line transducer (model P50, Gould Electronics, Cleveland, $\mathrm{OH}$ ). Pressure was measured at the tracheostomy site or in the subglottic trachea, in tracheostomized versus intact piglets, respectively. One-way inspiratory and expiratory valves (no. 2230B, Hans-Rudolph, Kansas City, MO) were attached to the endotracheal tube or nasal mask. For intact piglets, the total in vitro respiratory dead space was $6.5 \mathrm{~mL}$. The total respiratory circuit resistance was $1.1 \mathrm{~cm} \mathrm{H}_{2} \mathrm{O} / \mathrm{L} / \mathrm{min}$ at 0.5 to $5 \mathrm{~L} / \mathrm{min}$ flow. Through the inspiratory side of the respiratory circuit, humidified oxygen was supplied at $6-8 \mathrm{~L} / \mathrm{min}$ to ensure hyperoxia and prevent activation of peripheral chemoreceptors. Measurements of inspiratory flow were obtained by connecting the respiratory circuit to a pneumotachograph (Fleisch no. 0) with output to a differential pressure transducer and thence to a carrier amplifier. Volume was derived by integration of airflow using an integrator-amplifier (Gould) with a time constant of $100 \mathrm{~ms}$. Inspiratory and expiratory $\mathrm{CO}_{2}$ was monitored at the mask in some intact piglets with an infrared capnometer (Ohmeda 5200, Louisville, CO).

Inspiratory airflow, volume, airway pressures, ECoG, and arterial pressure were recorded on a strip chart (model 3800, Gould). After stable, baseline measurements were obtained, generalized seizures were induced with pentylenetetrazol, 100 $\mathrm{mg} / \mathrm{kg}$ (Sigma Chemical Co., St. Louis, MO) followed by 3-5 $\mathrm{mg} / \mathrm{kg}$ i.v. injections as required to obtain vigorous, intermittent, clinical, and electrical seizure activity. Respiratory responses were monitored for $30 \mathrm{~min}$ and were characterized during baseline control and representative ictal and interictal conditions. Arterial blood gases were obtained during baseline control conditions and 17-20 min after the onset of seizure activity, during an ictal discharge.

Peak inspiratory flow resistance plus external circuit resistance, in intact piglets, was calculated by averaging three epochs of five to seven consecutive, nonobstructed breaths. Each seizure epoch occurred during a separate ictal discharge for each piglet. An operational definition of apnea and obstruction was used in this study. The criteria for apnea were an average integrated inspiratory volume of less than $10 \mathrm{~mL}$ of greater than $20 \mathrm{~s}$ in duration. This definition was chosen to attempt to reduce the likelihood of including artifactual airflow introduced by movements of the pneumotachograph during seizure activity. In judging these effects, rapid, physical shaking of the pneumotachograph caused some airflow artifact, but little or no integrated volumes, with our respiratory apparatus. Central apnea was judged to be present with individual breaths where peak subglottic inspiratory pressures were greater than $-2 \mathrm{~cm} \mathrm{H}_{2} \mathrm{O}$, whereas obstructive apnea was defined as breaths during apneic periods where peak inspiratory pressures were less than $-10 \mathrm{~cm}_{2} \mathrm{O}$. Apneic breaths with airway pressures between -2 and $-10 \mathrm{~cm} \mathrm{H}_{2} \mathrm{O}$ were considered indeterminate.

Baseline mean arterial pressure was determined as [diastolic +0.33 (pulse pressure)] from strip records. Baseline temperature was manually recorded. Baseline variables were compared between intact versus tracheostomized groups using a one factor ANOVA. Respiratory responses were compared using a two-factor repeat measures ANOVA (i.e. airway group and condition), and a post hoc one-factor ANOVA when significance was achieved. Data were reported as mean $\pm \mathrm{SD}$, and significance was assumed at $p<0.05$.

To further examine the contribution of the vocal folds in contributing to subglottic resistances, a separate piglet was prepared. Experimental conditions were nearly identical to the intact piglets described above, except that the piglet was anesthetized with alphaxalone-alphadolone (Saffan ${ }^{\circledR}$, Pittman Moore of Europe). In addition, a Y-shaped tube was inserted to replace a section of the subglottic trachea. A flexible, fiberoptic scope (1.7-mm external diameter, Storz, St. Louis, MO) was advanced through a resealable membrane cephalad to visualize the glottis from below (see Fig. 6). Simultaneous subglottic pressure (inset; lower trace) and nasal airflow (inset; upper trace) were digitized along with the glottal picture, to characterize glottal patency under the various experimental conditions. Three operationally defined respiratory phases are shown: the onset of inspiration (the onset of negative airway pressure to less than $-2 \mathrm{~cm} \mathrm{H}_{2} \mathrm{O}$ ), peak inspiratory pressure (maximum inspiratory pressure between end-expiration and end-inspiration), and the onset of expiration (when airway pressure exceeds zero pressure as pressure increases during expiration). 


\section{RESULTS}

Group means for intact and tracheostomized groups were comparable in weight, and cardiac and most respiratory variables (Table 1). Tracheostomized piglets demonstrated significant hypocapnia and respiratory alkalosis under baseline conditions, compared with intact piglets $(p<0.05)$. The tracheostomized piglets were approximately $13 \%$ larger in body weight than intact piglets. Although mean Ve was somewhat larger in tracheostomized piglets, weight-adjusted values were not significantly different $(0.50 \pm 0.17 \mathrm{~L} / \mathrm{kg} \cdot \mathrm{min}$; mean $\pm \mathrm{SD}$, in intact versus $0.54 \pm 0.23$ in tracheostomized animals). Total, weight adjusted pentylenetetrazol doses were not significantly different for intact $(215 \pm 16.4 \mathrm{mg} / \mathrm{kg})$ versus tracheostomized $(218 \pm 17.7)$ piglets. As expected, peak inspiratory flow resistances were 3.5 times greater in intact animals under control conditions $(p<0.05)$. There was no evidence of rebreathing or mask leaks, and inspiratory $\mathrm{CO}_{2}$ values were less than $1 \%$ in all piglets monitored with capnometry.

A typical intact piglet (Fig. 1) demonstrates respiratory and ECoG responses during baseline control conditions (left panel) and during two sequential ictal discharges (characterized by high amplitude, rapid spiking activity on the ECoG; right panel). Transient incomplete mechanical obstruction is demonstrated in this intact piglet. During the very first ictal discharge in another intact piglet (Fig. 2), there is a 31-s period of apnea associated with $24 \mathrm{~s}$ of airway pressures where peak inspiratory pressures are zero. This central apnea was observed in three of the intact piglets. A typical tracing from a tracheostomized piglet (Fig. 3) demonstrates no evidence of increased resistance during ictal discharges. At the onset of an ictal discharge, fast tachypnea with small tidal volumes are observed in the tracheostomized piglet. Peak airflow values are increased substantially in tracheostomized piglets, but with small or no changes in airway pressures. Intact airway piglets demonstrated more modest increases in airflow, but much larger fluctuations in airway pressure.

During the first $20 \mathrm{~min}$ of seizures, three intact piglets demonstrated some evidence of central apnea $(0.22 \pm 0.18$ $\min$ ). When apnea was observed, it was always near the onset of an ictal discharge. All intact piglets demonstrated episodes of mechanical obstruction (mean $2.89 \pm 1.74 \mathrm{~min}$ ), whereas

Table 1. Comparison of baseline characteristics of intact and tracheostomized piglets

\begin{tabular}{lccc}
\hline \multicolumn{1}{c}{ Parameter } & Intact & Tracheostomized & $p$ value \\
\hline Number & 6 & 6 & - \\
Weight, $\mathrm{kg}$ & $8.6 \pm 0.38$ & $9.9 \pm 0.79$ & 0.005 \\
Temperature, ${ }^{\circ} \mathrm{C}$ & $37.9 \pm 0.90$ & $37.9 \pm 0.47$ & $\mathrm{NS}$ \\
Ketamine, $\mathrm{mg} / \mathrm{kg} \cdot \mathrm{h}$ & $14.1 \pm 0.78$ & $13.8 \pm 0.63$ & $\mathrm{NS}$ \\
Arterial pressure, $\mathrm{mm} \mathrm{Hg}$ & $79.5 \pm 8.39$ & $70.2 \pm 7.20$ & $\mathrm{NS}$ \\
$\mathrm{pH}$ & $7.37 \pm 0.06$ & $7.49 \pm 0.05$ & 0.002 \\
$\mathrm{PaO} 2, \mathrm{kPa}$ & $56.1 \pm 8.8$ & $54.0 \pm 7.7$ & $\mathrm{NS}$ \\
$\mathrm{Paco} 2, \mathrm{kPa}$ & $4.67 \pm 0.83$ & $3.32 \pm 0.51$ & 0.007 \\
$\mathrm{Base}$ excess, $\mathrm{mEq} / \mathrm{L}$ & $-4.45 \pm 2.37$ & $-3.87 \pm 2.02$ & $\mathrm{NS}$ \\
Ve, $\mathrm{L} / \mathrm{min}$ & $4.31 \pm 1.67$ & $5.36 \pm 2.14$ & $\mathrm{NS}$ \\
Resistance, $\mathrm{cm} \mathrm{H}{ }_{2} \mathrm{O} / \mathrm{L} \cdot \mathrm{s}$ & $58.6 \pm 18.6$ & $16.8 \pm 3.43$ & 0.0003 \\
\hline
\end{tabular}

Values are mean $\pm \mathrm{SD}$.

* Significant at $p<.05$, one-factor ANOVA.

\begin{abstract}
$0.25-$

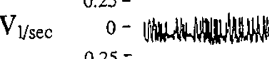
$0.25-$

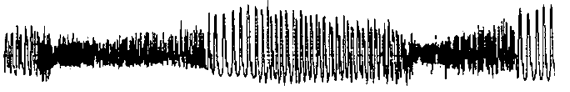

10 seconds

$\int V_{m 1}{ }_{150-}^{150-}$

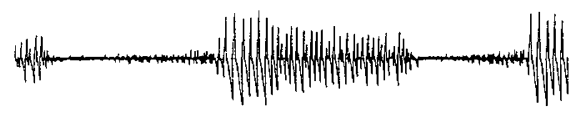

(+) $25-$

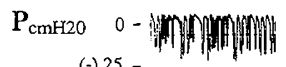
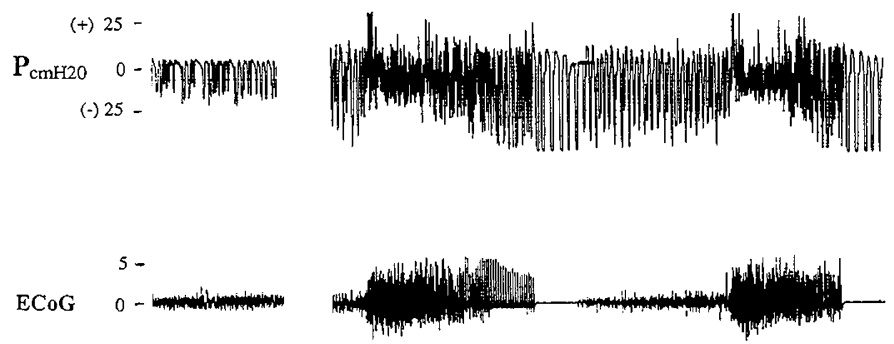

Figure 1. Respiratory obstruction in an intact piglet during experimental seizures. Airflow $(V)$, integrated airflow $(f V)$, subglottic pressure $(P)$, and ECoG at baseline (left panel) and during seizure discharges (right panel). Inspiratory (down on figure) and expiratory (up on figure) flows and volumes were recorded in this piglet. At the onset of each of the two ictal discharges, airflow is chaotic, volumes are less than $10 \mathrm{~mL}$, and inspiratory pressures are initially $-10-12 \mathrm{~cm} \mathrm{H}_{2} \mathrm{O}$. Airway pressures indicate transient expiratory, followed by inspiratory obstruction. The inspiratory pressures peak at approximately $-45 \mathrm{~cm} \mathrm{H}_{2} \mathrm{O}$ during this ictal discharge. At the onset of the interictal phase, when the ECOG is flat, tidal volumes are augmented, but inspiratory resistance is still increased compared with baseline.
\end{abstract}

tracheostomized piglets demonstrated no evidence of either apnea or obstruction $(p<0.05)$.

After 20 min of seizures, both groups demonstrated reductions in $\mathrm{pH}$ (Fig. 4) compared with baseline. The decrease in arterial $\mathrm{pH}$ was much greater in the intact (mean 0.26) versus tracheostomized (mean 0.11) piglets. Both groups of piglets had evidence of metabolic acidosis, whereas intact piglets demonstrated both respiratory and metabolic acidosis. Base excess decreased significantly from baseline values, in both intact $(-15.7 \pm 6.04)$ and tracheostomized $(-12.1 \pm 3.59 ; p$ $<0.05)$ piglets. Intact piglets demonstrated much greater increases in $\mathrm{PaCO}_{2}$ (mean $21.4 \mathrm{~mm} \mathrm{Hg}$; Fig. 4) than tracheostomized piglets (mean 2.4).

Tracheostomized piglets demonstrated significant increases in Ve during ictal (mean $+7.9 \mathrm{~L} / \mathrm{min}$ ) and interictal (mean $+7.3 \mathrm{~L} / \mathrm{min}$ ) phases of seizures $(p<0.05$; Fig. 5), whereas intact piglets did not (mean ictal $-0.02 \mathrm{~L} / \mathrm{min}$ and mean interictal $+2.1 \mathrm{~L} / \mathrm{min}$ ), when compared with baseline conditions $(p=\mathrm{NS})$. Intact piglets demonstrated a nearly 4-fold increase in peak subglottic resistances (mean $+134 \mathrm{~cm} \mathrm{H}_{2} \mathrm{O}$ / $\mathrm{L} \cdot \mathrm{s}$ ) during seizures (Fig. 5, right panel) compared with baseline $(p<0.05)$. No significant change in respiratory system resistance was apparent during seizures (ictal mean +2.7 and interictal mean $\left.0.5 \mathrm{~cm} \mathrm{H}_{2} \mathrm{O} / \mathrm{L} \cdot \mathrm{s}\right)$ in tracheostomized piglets $(p$ $=\mathrm{NS}$ ). In addition, no significant difference in mean $\mathrm{PaO}_{2}$ values during seizures was observed for intact $(357 \pm 121$ $\mathrm{mm} \mathrm{Hg}$ ) versus tracheostomized $(393 \pm 45)$ piglets.

In the piglet prepared for glottal patency recordings, the vocal folds responded appropriately with wide dilation during 


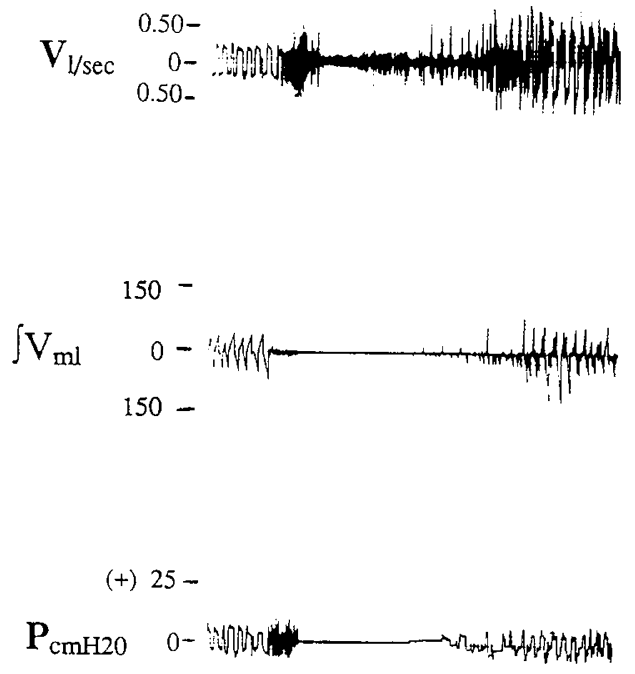

(-) $25-$

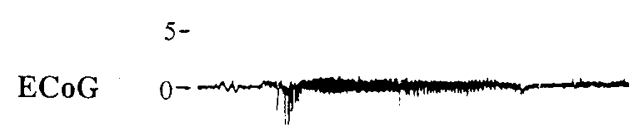

Figure 2. Central apnea during experimental seizures in an intact piglet. Airflow $(V)$, integrated airflow $\left(\int V\right)$, subglottic pressure $(P)$, and ECoG during an initial seizure discharge. There is a 31-s period of apnea associated with 24 $s$ of airway pressures where peak inspiratory pressures are zero. During the accompanying interictal period, there is a sudden increase in airflow and subglottic pressures.
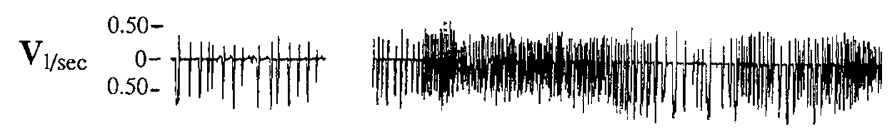

$\int V_{\mathrm{ml}}{ }^{150-} 0^{-}$
(+) $25-$

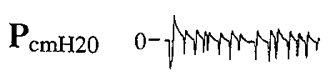

(-) $25-$

$5-$

ECoG

Figure 3. Respiratory responses in a tracheostomized piglet. Airflow (V), integrated airflow $\left(\int V\right)$, tracheal pressure $(P)$, and ECoG at baseline (left panel) and during two ictal discharges (right panel). The right panel demonstrates increased airflow and pressure during a vigorous generalized seizure discharge. There is no evidence of apnea or airflow obstruction in this piglet. The rapid tachypneas during the ictal discharges are typical of the tracheostomized piglets.

hypoxic-hypercapnic rebreathing, whereas during the ictal phases of pentylenetetrazol-induced seizures, the glottis was tonically adducted. Panels from representative, single breaths (Fig. 6) at the onset of inspiration (top row), peak inspiratory pressure (middle row), and the onset of expiration (bottom row) show glottal dilation at the peak of inspiratory flow under baseline and interictal, but not seizure conditions. During the
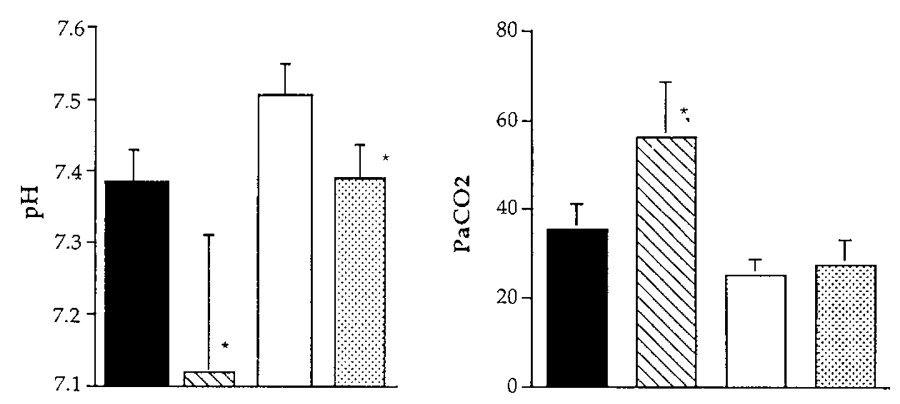

Figure 4. Comparison of arterial $\mathrm{pH}$ and $\mathrm{PaCO}_{2}(\mathrm{~mm} \mathrm{Hg})$ of intact $v s$ tracheotomized piglets under baseline control conditions and after seizures. The intact group under baseline conditions (solid bars), the intact group under seizure conditions (cross-hatched bars), tracheostomized group under baseline conditions (open bars), and tracheostomized group under seizure conditions (stippled bars) are mean $\pm \mathrm{SD}$ values. The asterisk $\left({ }^{*}\right)$ indicates significantly different from control values during seizures.
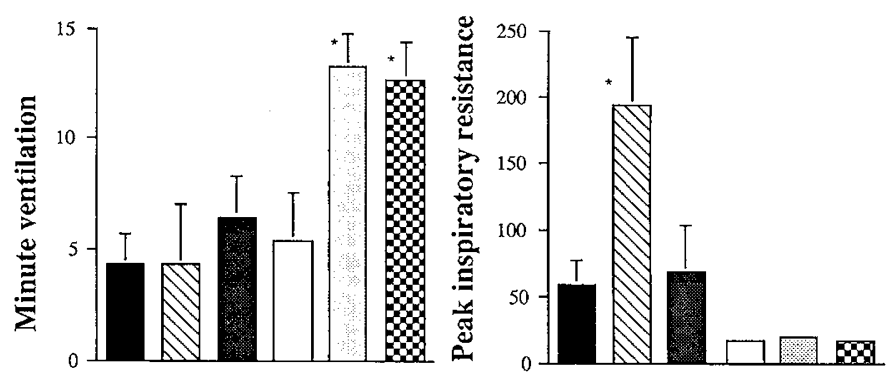

Figure 5. Comparison of minute ventilation ( $\mathrm{Ve}, \mathrm{L} / \mathrm{min}$ ) and peak inspiratory flow resistances $\left.\left(\mathrm{cm} \mathrm{H}_{2} \mathrm{O}\right) / \mathrm{L} \cdot \mathrm{s}\right)$ of intact $v s$ tracheotomized piglets under baseline control conditions and after seizures. Intact group under baseline condition (solid bars), intact group under ictal conditions (cross-hatched bars), intact group under interictal conditions (dark stippled bars), tracheostomized group under baseline conditions (open bars), tracheostomized group under ictal conditions (lightly stippled bars), and tracheostomized group under interictal conditions (alternating dark and light boxes) are mean $\pm \mathrm{SD}$ values. The asterisk $\left(^{*}\right)$ indicates significantly different from control values during seizures.

ictal phase of seizures, glottal closure is evident throughout the respiratory cycle despite attempted inspiratory efforts, as indicated by the upper airway pressure fluctuations (inset, lower trace). During the interictal phase of seizures, glottal closure is increased at the onset of expiration over that during baseline conditions.

\section{DISCUSSION}

The present study demonstrates the importance of the upper airway in determining respiratory responses to experimental seizures induced with pentylenetetrazol. Piglets with intact upper airways developed hypoventilation, respiratory acidosis, and significant increases in subglottic airway resistances during seizures, whereas piglets with bypassed upper airways did not. Tracheostomized piglets demonstrated significant increases in minute ventilation during seizures. The site of upper airway obstruction and increased resistance in this study has not been defined. Potential sites of upper airway obstruction in this study include the larynx, pharynx, and nasal ostia. Overly snug mask fit may have contributed to increased resistance in intact piglets, but was no different during baseline and seizure conditions. One potential explanation for these increased subglot- 

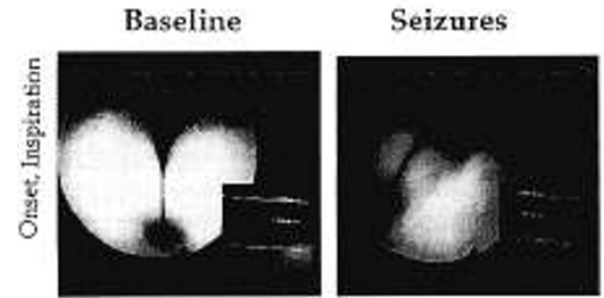

Interictal
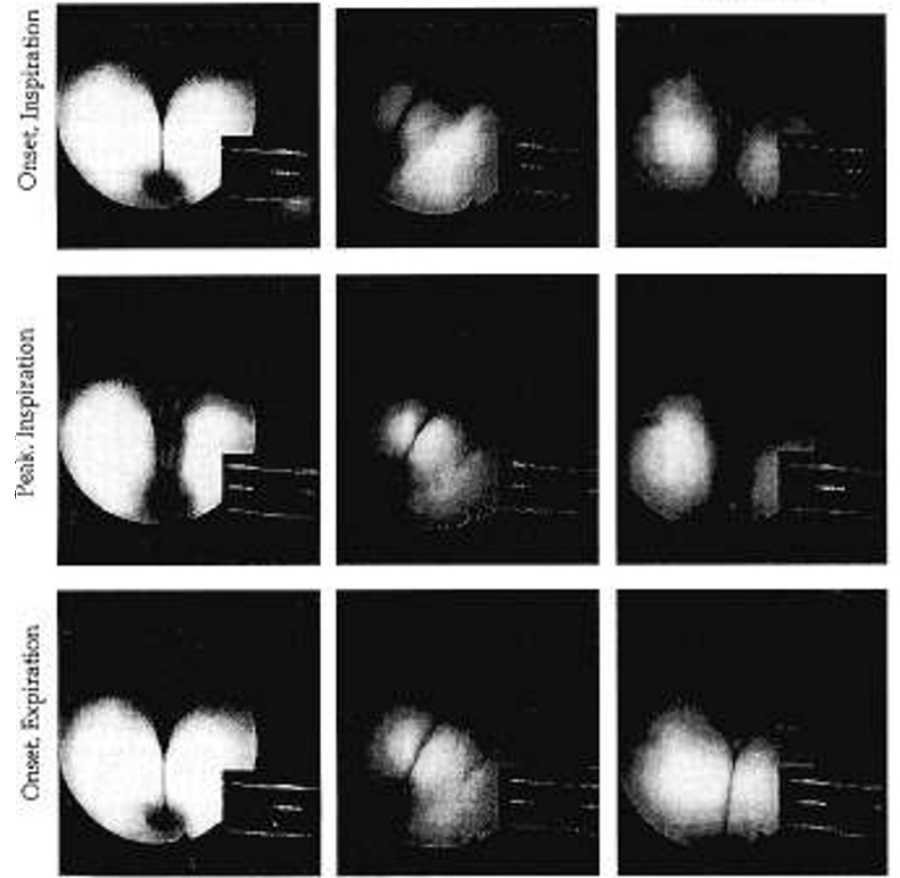

Figure 6. Glottal patency in a spontaneously breathing piglet during experimental seizures. Digitized frames of the glottal area viewed from the caudal trachea under baseline control (left three panels), ictal (middle three panels), and interictal (right three panels) conditions in a hyperoxic piglet with seizures induced with pentylenetetrazol. The panels are from representative, single breaths at the onset of inspiration (top row), peak inspiratory pressure (middle row), and the onset of expiration (bottom row). The inset in each frame shows simultaneous inspiratory flow (top trace, inspiration down) and subglottic pressure (bottom, negative pressure down), with the farthest right hand side of these tracings corresponding to the glottal picture. During the ictal phase of seizures, glottal closure is evident throughout the respiratory cycle despite attempted inspiratory efforts. During the interictal phase of seizures, glottal closure is increased at the onset of expiration over that during baseline conditions.

tic resistances and apnea seen in intact piglets is provided from a single piglet. Excessive vocal fold adduction provides a site of increased resistance and may result in increased expiratory volumes. The lack of significant increases in resistance in tracheostomized piglets during seizures suggests that the chest and lower respiratory system mechanical properties were not significantly altered by these seizures. This view is supported by preliminary evidence in similarly prepared piglets (13).

The inability of the CNS to properly modulate upper and lower airway responses to fictive seizures in this study indicates a potential mechanism for respiratory complications during seizures, including sudden death in epilepsy. Entrainment of respiratory motor nerve activity in paralyzed, ventilated cats during subcortically induced seizures has recently been shown (9). These cats demonstrated reduced phrenic activation to inhaled $\mathrm{CO}_{2}$ during entrained ictal, but not interictal, periods of seizure discharges. Entrainment during seizures may have selective effects on various respiratory motor nerves, with the phrenic nerve showing less entrainment than nasolabial and hypoglossal nerves (11). Selective activation or depression of respiratory motor nerves may degrade the normal phasic relationships between upper and lower respiratory muscles, partic- ularly during critical periods of development (14). The short periods of central apnea, which typically occurred at the onset of an ictal discharge, occurred only in half of the airway intact piglets in this study. One potential mechanism which may have produced central respiratory inhibition is excessive vocal fold closure, in these vagally intact animals. Activation of pulmonary stretch receptors by air trapping or attempted expiration against a closed glottis may have accounted for these transient central apneas.

The interpretation of mechanical obstruction in this study is made difficult by movement of the pneumotachograph during seizures. This movement created a rapid oscillation of small amounts of air and represents motion artifact or ineffective respiratory efforts. Integrated airflow signals during these periods show little evidence of inspiratory flow and as such integrated airflow was used to judge minute ventilation and apnea. Elimination of dead space probably accounted for the baseline respiratory alkalosis in the tracheostomized, but not intact, piglets. Anesthesia levels, body temperature, and oxygenation were no different between these groups.

The human upper airway requires muscular support and laryngeal patency for unobstructed airflow to occur. The activity of supporting muscles counteracts the collapsing pressure created in the upper airway during inspiration (12). Coordinated muscular activity controlled by respiratory centers in the brainstem and relayed to peripheral efferents is required for maintenance of laryngeal and non-laryngeal upper airway patency (15). Generalized seizure activity is associated with the loss of coordinated muscular activity, resulting clinically in falls and tongue biting. This lack of CNS coordination during seizures may be influenced by abnormal respiratory neuromuscular timing, excessive respiratory drive to the diaphragm, and reduced or abnormal upper airway stabilizing activity. For example, if peripheral laryngeal adductor activity during seizures is tonic or out of phase with phrenic activation, one site of increased airway resistance during seizures could be localized at the vocal folds.

An understanding of respiration during seizures is important to define the site(s) and pathophysiology of impairment so that current treatment strategies can be modified. The current study provides evidence of increased subglottic obstruction and excessive laryngeal adduction in a piglet seizure model. Identification of anticonvulsants which facilitate coordination between neurologic drive and phasic inspiratory airway dilatation may be beneficial for reducing respiratory complications during seizure management. In addition to understanding respiratory complications of seizures, these data may be relevant to the pathophysiology of SIDS, inasmuch as $80 \%$ of more of these infants have pathologic evidence consistent with a terminal airway obstruction (16). Recent data demonstrates that many infants with recurrent apparent life-threatening events, thought to be a risk factor for SIDS, have evidence of seizure activity (17). Further, seizure activity is common during sleep, is difficult to recognize in neonates, and may account for the lack of arousal during hypoxic stimulation occurring during preterminal conditions in SIDS victims $(18,19)$. 


\section{CONCLUSIONS}

The present model demonstrates that upper airway patency and resistances are important determinants of respiratory responses during generalized seizures. Ineffective respiration during seizures likely results from increases in upper airway resistances despite increases in central respiratory drive. Further examination of upper airway controls during seizures appears warranted.

Acknowledgments. The authors thank Alan Kadison, B.S., and Diane Hartzog for their excellent technical and organizational assistance with this project, respectively. We also thank Robert Kanter, M.D., for his review of the manuscript.

\section{REFERENCES}

1. Leppick IE, Derivan AT, Homan RW, Walker J, Ramsay RE, Patrick B 1983 Double-blind study of lorazepam and diazepam in status epilepticus. JAMA 249:1452-1454

2. Stambouly JJ, Pollack MM 1990 Jatrogenic illness in pediatric critical care. Crit Care Med 18:1248-1251

3. Chiulli DA, Terndrup TE, Kanter RK 1991 The influence of diazepam or lorazepam on the frequency of endotracheal intubation in childhood status epilepticus. J Emerg Med 9:13-17

4. Navelet Y, Wood C, Robieux I, Tardieu M 1989 Seizures presenting as apnea. Arch Dis Child 19:199-207
5. Lown B, Verrier RL 1978 Neural factors and sudden death. In: Schwartz PJ, Brown AM, Malliani A, Zanchetti A (eds) Perspectives in Cardiovascular Research. Neural Mechanisms in Cardiac Arrhythmias. Raven Press, New York, pp 87-98

6. Earnest MP, Thomas GE, Eden RA, Hossack KF 1992 The sudden unexplained death in epilepsy: Demographic, clinical and postmortem features. Epilepsia 33:310-316

7. Paydarfar D, Eldridge FL, Scott SC, Dowell RT, Wagner PG 1991 Respiratory responses to focal and generalized seizures in cats. Am J Physiol 260:R934--R940

8. Terndrup TE, Paskanik AM, Fordyce WE, Kanter RK 1993 Development of a piglet model of status epilepticus: Preliminary results. Ann Emerg Med 22:164-170

9. Paydarfar D, Eldridge FL, Wagner PG, Dowell RT 1992 Neural respiratory responses to cortically induced seizures in cats. Respir Physiol 89:225-237

10. Terndrup TE, Starr F, Fordyce WE 1994 A piglet model of status epilepticus: Comparison of cardiorespiratory and metabolic changes with two methods of pentylenetetrazol administration. Ann Emerg Med 23:470-479

11. Terndrup TE, Knuth SL, Gdovin MJ, Bartlett D 1994 Respiratory motor nerve activities during fictive seizures. FASEB J 8:A910(abstr)

12. Wiegand DA, Latz B, Zwillich CW, Wiegand L 1990 Geniohyoid muscle activity in normal men during wakefulness and sleep. J Appl Physiol 69:1262-1269

13. Keneck E, Terndrup TE, Fordyce WE 1993 Respiratory mechanics during seizures in spontaneously breathing piglets. Pediatr Res 33:372A(abstr)

14. Eichenwald EC, Howell RG, Kosch PC, Ungarelli RA, Lindsey J, Stark AR 1992 Developmental changes in sequential activation of laryngeal abductor muscle and diaphragm in infants. J Appl Physiol 73:1425-1431

15. Bartlett D, Jr 1989 Respiratory functions of the larynx. Physiol Rev 69:33-57

16. Willinger M, James LS, Catz C 1991 Defining the Sudden Infant Death Syndrome: Deliberations of an expert panel convened by the National Institute of Child Health and Human Development. Pediatr Pathol 11:677- 684

17. Poets CF, Samuels MP, Noyes JP, Hewertson J, Hartmann H, Holder A, Southall DP 1993 Home event recordings of oxygenation, breathing movements, and heart rate and rhythmn in infants with recurrent life-threatening events. J Pediatr 123:693-701

18. Mizrahi EM 1987 Neonatal seizures: Problems in diagnosis and classification. Epilepsia Suppl 1:46-55

19. Harper RM 1986 State-related physiological changes and risk for sudden infant death syndrome. Aust Paediatr J 22(suppl):55-58 